\title{
Evaluation of Acoustical Properties of an Auditorium after a Modernisation Program
}

\author{
A. Czerwiński AND Z. DZIECHCIOWSKI* \\ Faculty of Mechanical Engineering, Institute of Machine Design, Cracow University of Technology \\ al. Jana Pawła II 37, 31-864 Kraków, Poland
}

\begin{abstract}
This study summarises and compares the measurement results of acoustical properties of an auditorium located on the campus of the Faculty of Mechanical Engineering at the Cracow University of Technology. The auditorium was thoroughly modernised and its acoustic features adapted. Measurements of the room acoustics were first taken prior to the modernisation program and were repeated after completion of the modernisation works. Evaluation of auditorium acoustics was based on the following parameters: reverberation time, early/late energy ratio (clarity) $C_{50}$, early decay time, speech intelligibility indices, and uniformity of sound distribution. The effect of the modernisation program on levels of those parameters are explored and conformity to the design objectives is analysed.
\end{abstract}

DOI: 10.12693/APhysPolA.125.A-71

PACS: 43.55.Br, 43.55.Fw, 43.55.Hy

\section{Introduction}

Lecture halls and auditoriums in schools and universities belong to the group of rooms acoustic quality of which needs to be tested at the stage of design or modernisation. Such approach helps to eliminate certain design errors which might adversely affect acoustical properties of the room. Applicable guidelines have to be consulted at the stage of design in order to be able to select optimal acoustic parameters of the room's interior. The literature on the subject abounds in guidelines to acoustic projects and reports on measurements and calculation of acoustic parameters. Paper [1] provides a review of international standards applicable to design of school rooms.

Room design and modernisation projects ought to be preceded by acoustic measurements of their interiors. Acoustic measurements need also to be taken after completion of modernisation projects to evaluate the acoustic parameters of the modernised room. Such measurements may reveal the need for further corrective actions. A similar procedure adopted for evaluating classrooms is reported in [2]. Acoustic measurements prior to a modernisation program allow for defining the objectives most useful in acoustic calculations.

This paper summarises results of evaluation of acoustical conditions in a thoroughly modernised auditorium located on the campus of the Mechanical Faculty of the Cracow University of Technology in Czyżyny (Kraków). Acoustic measurements were first taken prior to the modernisation program. The modernization works carried out within the framework of the project realized by the Cracow University of Technology have been preceded by acoustic calculations of the auditorium interior. According to the adopted project methodology, acoustic measurements were repeated after completion of modernisa-

*corresponding author; e-mail: dziechci@mech.pk.edu.pl tion work in order to compare the calculated results with the measurement data.

\section{Principles of evaluating the effect of noise on} humans inside the buildings

Acoustical properties of the auditorium are established based on measurements and calculations of selected objective indicators such as the reverberation time (RT) $T_{20}$, the early decay time (EDT), the early/late sound energy ratio $C_{50}$, speech intelligibility indices STI and RASTI, and the sound level distribution.

The optimum reverberation time for rooms intended for speech transmission depends on their volume. In accordance with DIN 18041 [3], the optimum reverberation time for the investigated rooms is given by

$$
T_{\mathrm{opt}}=0.32 \cdot \log (V)-0.17[\mathrm{~s}] \text {, }
$$

where $V\left[\mathrm{~m}^{3}\right]$ is the volume of the auditorium.

It is assumed that the reverberation times for particular octave frequencies should fall in the tolerance range from 0.8 to $1.2 T_{\text {opt }}$ (for frequencies $250 \mathrm{~Hz}, 500 \mathrm{~Hz}$, $1000 \mathrm{~Hz}$, and $2000 \mathrm{~Hz}$ ) and from 0.65 to $1.2 T_{\mathrm{opt}}$ (for frequencies $125 \mathrm{~Hz}$ and $4000 \mathrm{~Hz}$ ).

The EDT is defined as the time interval after which the energy of an acoustic field drops by $10 \mathrm{~dB}$ from the steady level after the excitation stops. In case of the ideally exponential curve of decay in the diffusion field, the expected EDT value is equal to the reverberation time.

Subjectively perceived sound clarity $C_{50}$ is defined as the logarithm of the ratio of the impulse response in the time interval $50 \mathrm{~ms}$ after the direct sound to sound energy after $50 \mathrm{~ms}$. In order that the parameter $C_{50}$ based on sound energy should be used in direct evaluation of speech clarity, it has to be spectrally weighted and averaged. This formula, given by (2), is proposed in [4] where the frequency-weighted index $C_{50 \text { (spav) }}$ is defined as

$$
\begin{aligned}
& C_{50(\text { spav })}=0.15 \cdot C_{50(500 \mathrm{~Hz})}+0.25 \cdot C_{50(1000 \mathrm{~Hz})} \\
& \quad+0.35 \cdot C_{50(2000 \mathrm{~Hz})}+0.25 \cdot C_{50(4000 \mathrm{~Hz})} .
\end{aligned}
$$

The interpretation of the variability of speech intelligibility index represented by $C_{50(\text { spav })}$, is as follows: 
$C_{50 \text { spav })} \in[-15 \mathrm{~dB},-7 \mathrm{~dB}]-$ "Bad"; $[-7 \mathrm{~dB}, 2 \mathrm{~dB}]-$ "Poor"; [2 dB, 7 dB] — "Good"; [7 dB, $15 \mathrm{~dB}]$ — "Excellent".

Speech intelligibility indices RASTI and STI based on the impulse response are used to find the modulation transfer function $m(F)$ in accordance with [5]. The values of $m(F)$ are obtained for selected different modulation frequencies and octave bands. The values of STI index are determined for the male $\left(S T I_{(m)}\right)$ and female $\left(S T I_{(f)}\right)$ voices separately.

Variability ranges of STI and RASTI indices and the equivalent subjective judgement of the speech intelligibility are: $0.0-0.3$ - "Bad"; 0.3-0.45 — "Poor"; 0.45-0.6 — "Fair"; 0.6-0.75 — "Good"; 0.75-1.0 — "Excellent".

\section{Test object}

Tests were performed in an auditorium characterised with amphitheatrical layout. The isometric drawing of the auditorium is shown in Fig 1.

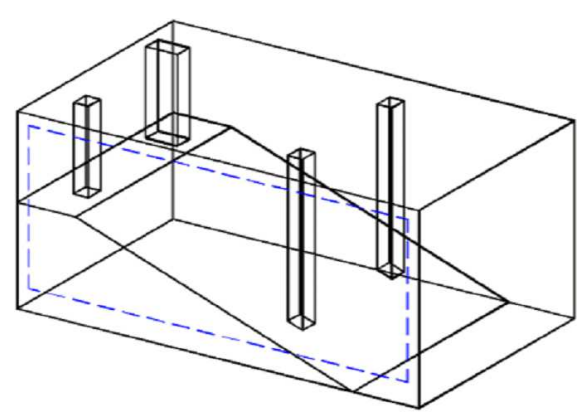

Fig. 1. Isometric drawing of the investigated auditorium.

The maximum dimensions in the orthogonal projection of the room are $13.2 \mathrm{~m} \times 11.10 \mathrm{~m} \times 6.4 \mathrm{~m}$ (length $\times$ width $\times$ height). The seats are arranged as in an amphitheatre. A large portion of one of the walls is made of glass panels (the glass surface is indicated with broken lines in Fig. 1). The auditorium was thoroughly modernised and its condition prior and after the modernisation program is summarised below.

\subsection{Auditorium before modernisation}

The walls were covered with wooden wainscoting, painted with colourless varnish. There was a lacquered wooden parquet on the floor. The ceiling was flat, finished with calcium sulphate plaster and a layer of emulsion paint. The seats and desks were made of lacquered wood. On one of the walls there was a sliding board made of plywood. A large section $(75 \%)$ of one of the walls was made of glass panels. On the wall with windows there were vertical window shutters, made of cloth.

\subsection{Auditorium after modernisation}

The auditorium was re-designed and certain readjustments were made. The floor and wall covering as well as the window woodwork were altered. The ceiling in the teacher's section was reshaped and given the stairslike wrinkled profile. On the side walls and on the wall with the blackboard, acoustic elements in the form of non-perforated lining panels filled with rock wool were mounted (on the side wall the lining is $2 \mathrm{~m}$ high, on the wall with the blackboard it covers the whole surface). On the side wall, above acoustic panels, there is a gypsumcardboard lining painted with a layer of emulsion paint. There is a suspended ceiling made of Ecophon panels having different sound absorption coefficients. In the front section of the room (in the teacher's area), the ceiling has a variable cross-profile, forming a sound-scattering feature. In other room sections the ceiling is flat. The floor is fitted with a homogeneous covering of the Tarkett type. The auditorium is furnished with simple, hard-surfaced furniture made of lacquered colourless plywood, with no upholstery. The side wall is made of glass panels $(95 \%)$. There are PVC-coated cloth shutters by the windows.

\section{Measurements - acoustical conditions and measuring instrumentation}

Measurements were taken at a grid of points inside the auditorium. The measurements were performed in 41 measurement points location of which is presented in Fig. 2. A microphone was positioned at about $1.2 \mathrm{~m}$

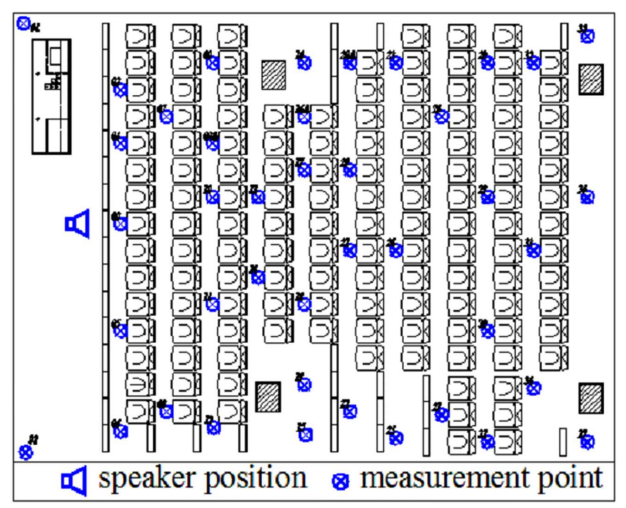

Fig. 2. Location of a speaker and measurement points.

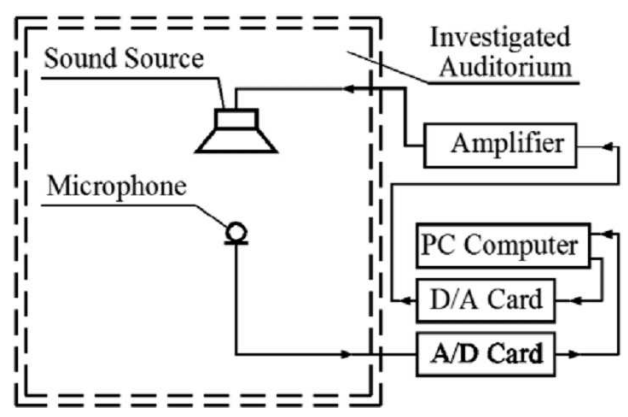

Fig. 3. Measuring equipment.

above the floor level. The measuring system is shown in Fig. 3. In the measurement program, an active system of loudspeakers was used located in the teacher's place (Fig. 2) at the altitude of $1.6 \mathrm{~m}$. The measurement procedure was supported by the ARTA Software. Signals 
generated from D/A (EDIROL UA-EX) card were delivered to the system of loudspeakers, and signals from the microphone with a pre-amplifier (B\&K 4155) were sent to the ARTA program via a sound level meter (B\&K 2230) and $\mathrm{A} / \mathrm{D}$ card. Based on the generated and measured signal, the impulse response was determined. Two types of signals were used in the measurements: noise signals using the filters of the speech type to determine RASTI and STI indices (the noise level at the distance of $1 \mathrm{~m}$ from the loudspeakers was set to $68 \mathrm{~dB}(\mathrm{~A}))$ and higherlevel MLS signals to determine the remaining acoustic parameters.

\section{Measurement results}

\subsection{Reverberation time}

Reverberation time RT values were determined at each measurement point for 6 octave bands $(125-4000 \mathrm{~Hz})$. Measurement data are summarised in Fig. 4. Error bars represent values of standard deviation of the results, being the measure of variability of the given parameter within the investigated room. The optimum values of reverberation time (in accordance with applicable standard [3]) are indicated with broken lines.

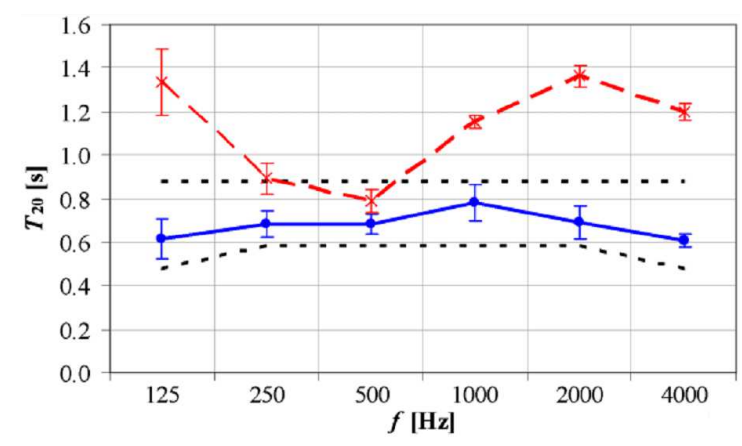

Fig. 4. Measured reverberation time $T_{20}$ (dashed line - before, solid line - after modernisation).

When compared to the conditions before the modernisation, the RT values were significantly reduced (by 10$50 \%$, depending on frequency). Thus obtained RT values fall in the optimal range for the given type of halls. RT values are similar throughout the considered frequency range, revealing a slight increase for the $1 \mathrm{kHz}$ band. The values of the standard deviation indicate that investigated parameters should vary very little within the auditorium.

\subsection{Early decay time EDT}

Measurement results of the early decay time EDT in octave bands are plotted in Fig. 5, providing also the standard deviation of results registered within the auditorium. The optimum range $\pm 10 \%$ of reverberation time for the EDT is indicated with broken lines.

EDT values after modernisation tend to be shorter than the optimum ones derived on the basis of $T_{20}$ which is indicative of too high contribution of the direct sound wave, suggestive of low scattering. As a result, the overall

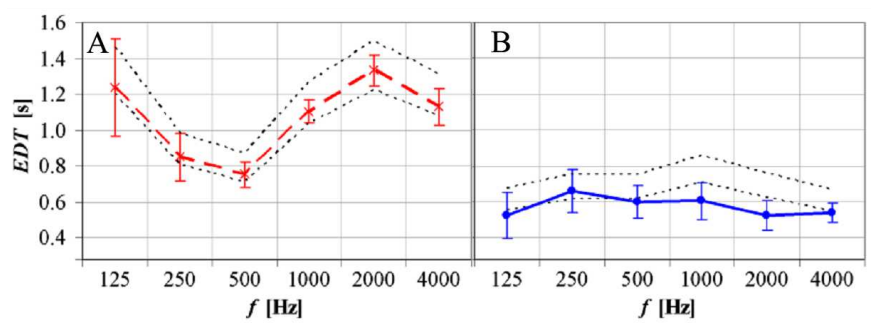

Fig. 5. Measurement data of EDT in the auditorium (A - before, B - after modernisation).

impression is that of excessive damping. As acoustic scattering levels in the auditorium before modernisation were decidedly higher, the parameters EDT and $T_{20}$ would be better correlated.

\subsection{Speech intelligibility}

Speech intelligibility was evaluated based on objective descriptors such as $C_{50 \text { (spav) }}$, RASTI, and STI. Average values of those parameters and their standard deviations are summarised in Table I.

TABLE I

Speech intelligibility parameters values.

\begin{tabular}{l|c|c|c|c}
\hline \hline Adaptation & RASTI & $S T I_{(m)}$ & $S T I_{(f)}$ & $C_{50(\text { spav })}[\mathrm{dB}]$ \\
\hline before & $0.61 \pm 0.04$ & $0.60 \pm 0.05$ & $0.60 \pm 0.06$ & $1.28 \pm 1.73$ \\
after & $0.75 \pm 0.04$ & $0.72 \pm 0.05$ & $0.72 \pm 0.05$ & $6.38 \pm 1.98$
\end{tabular}

The distribution patterns of these indices are shown in Figs. 6 and 7. Histograms of each parameter are shown in Fig. 8.

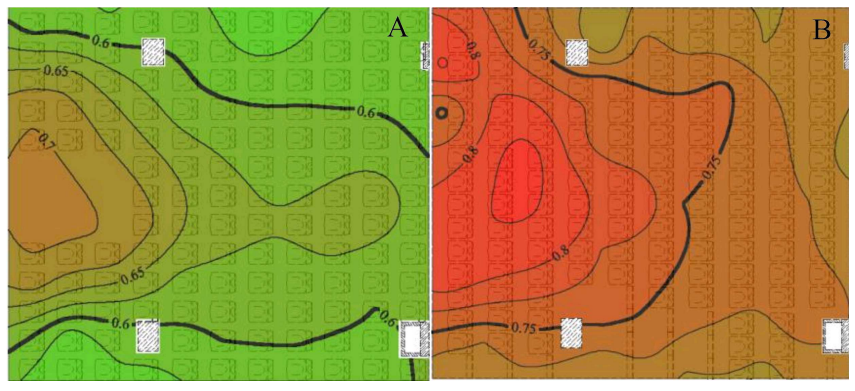

Fig. 6. RASTI index distribution (A - before modernisation, B - after modernisation).

Table II summarises the ratios (percentage fractions) of the room's surface area corresponding to particular speech intelligibility evaluations (in terms of all analysed parameters).

The analysis of these parameters reveals a major improvement in speech intelligibility within the entire auditorium. Averaged values of relevant parameters suggest that the speech intelligibility in the auditorium prior to modernisation could be considered as fair or good. After the modernisation program, the speech intelligibility 


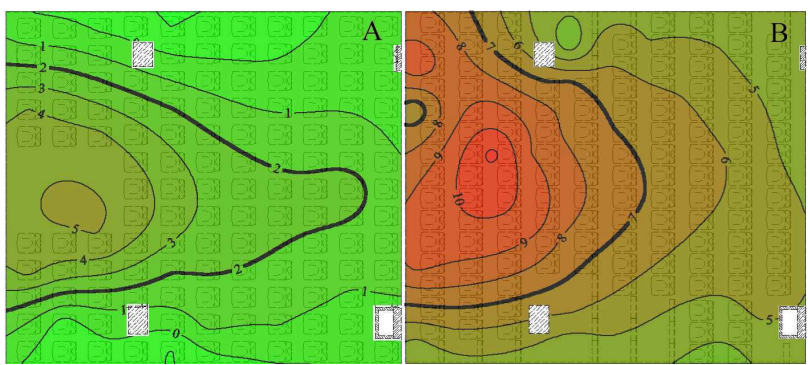

Fig. 7. Distribution of $C_{50 \text { (spav) }}(\mathrm{A}-$ before modernisation, B - after modernisation).

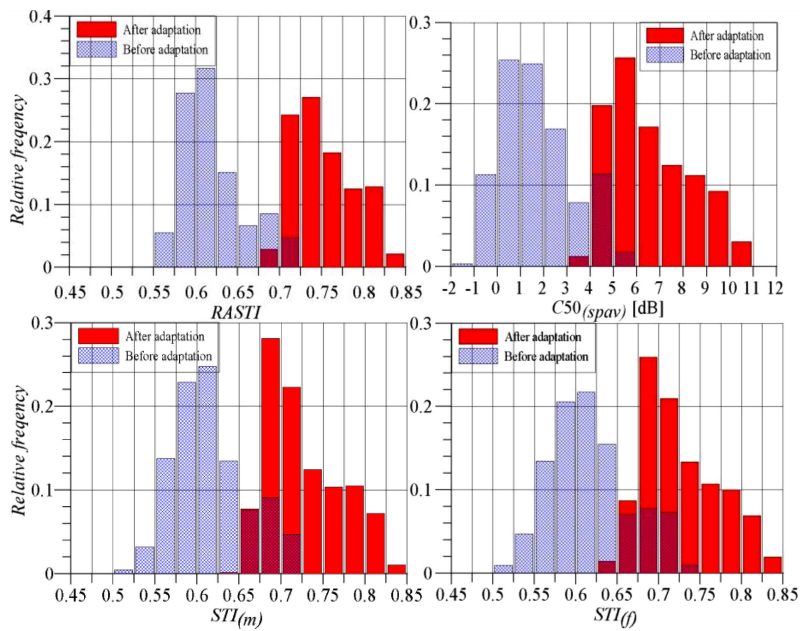

Fig. 8. Histogram of RASTI, $C_{50 \text { (spav) }}$ and STI index (before and after modernisation).

improved, becoming good / excellent. These indicators tend to vary very little from seat to seat in the room, both before and after modernisation. After the modernisation program, speech intelligibility at each position in the auditorium was at least good (as evidenced by all analysed parameters) whilst for $1 / 3$ of seats, the speech intelligibility was found to be excellent (which never occurred before modernisation). The most significant improvement took place in the front and middle sections of the auditorium - particularly next to the exterior wall (windows).

Major differences were observed in evaluations based

TABLE II

Fraction [\%] of the room's surface area corresponding to the given speech intelligibility scores.

\begin{tabular}{l|c|c|c|c|c|c}
\hline \hline & \multicolumn{2}{|c|}{ fair } & \multicolumn{2}{c|}{ good } & \multicolumn{2}{c}{ excelent } \\
\hline & before & after & before & after & before & after \\
\hline RASTI & 33 & - & 67 & 54 & - & 46 \\
$S T I_{(m)}$ & 40 & - & 60 & 71 & - & 29 \\
$S T I_{(f)}$ & 40 & - & 60 & 70 & - & 30 \\
$C_{50(\text { spav })}$ & 62 & - & 38 & 64 & - & 36
\end{tabular}

on the analysed parameters: RASTI indicates better clarity than the other parameters, both before and after the modernisation program; both $S T I_{(m)}$ and $S T I_{(f)}$ show a good conformity with clarity evaluations; the index $C_{50 \text { (spav) }}$ correlates well with the remaining parameters in the auditorium after modernisation whilst before the modernisation the intelligibility scores were lower. To better highlight the differences in the speech intelligibility evaluations based on individual parameters, the measurement data are given in the form of a graph. Fig. 9 plots the relationship between $C_{50 \text { (spav) }}$ and RASTI.

It is apparent that the speech intelligibility evaluations based on parameter $C_{50 \text { (spav) }}$ and RASTI correlate better when the index values are higher (for good or excellent clarity). In the case of lower speech intelligibility scores, evaluation based on $C_{50 \text { (spav) }}$ is suggestive of poorer clarity than that based on RASTI. The dash-dot line in Fig. 9 plots the relationship between $C_{50 \text { (spav) }}$ and RASTI, as suggested in [6]. In that case $C_{50(\text { spav) }}$ and RASTI would show good conformity.

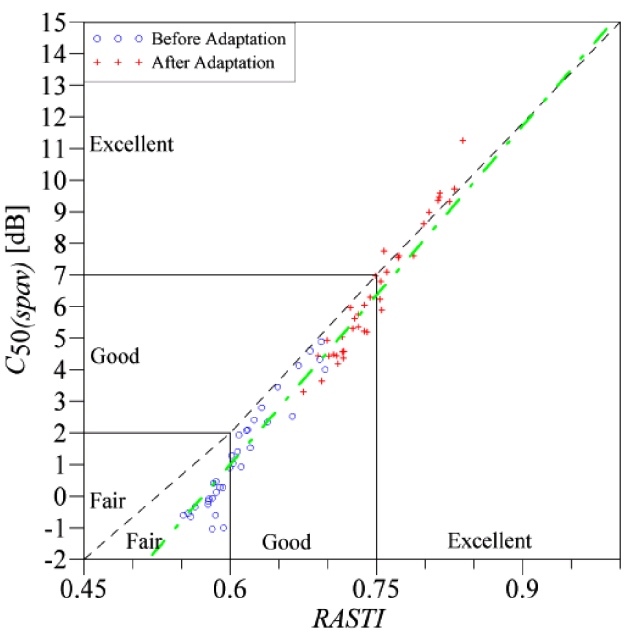

Fig. 9. Differences in speech intelligibility evaluations - $C_{50(\text { spav })}$ vs. RASTI.

\subsection{Sound level distribution}

In order to evaluate the uniformity of sound distribution in the auditorium (without the use of electroacoustic system), variations of sound pressure levels were graphed in the map format (Fig. 10). The benchmark was taken to be the value registered at a point located at the distance of $1 \mathrm{~m}$ from the loudspeaker. The maps show that the sound uniformity, particularly in the rear section of the hall (reduction by $3 \mathrm{~dB}$ ), has slightly deteriorated. This degradation is attributable to smaller contribution of the reverberation field in the modernised auditorium. As it was mentioned in earlier sections relative to the EDT index (Sect 5.2), the sound level is determined chiefly by the direct waves. There is no control of early reflection energy ratios due to application of sound guiding and scattering elements. Excessive reduction of 


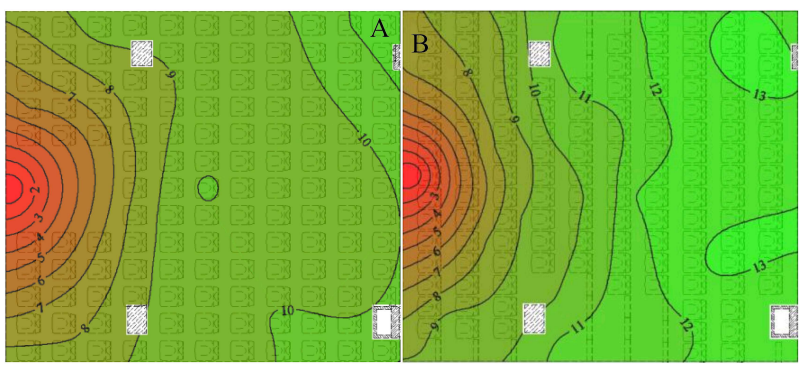

Fig. 10. Changes in sound pressure levels $(\mathrm{A}-$ before modernisation, $\mathrm{B}$ - after modernisation).

the sound level may affect the speech intelligibility in the case of higher background noise levels.

The sound scattering can be enhanced through increasing the acoustic scattering coefficient of the scattering structures mounted in the ceiling. These issues are described in more detail in [7], where the authors investigated the behaviour of various scattering structures, similar to those used in the modernised auditorium.

\section{Acoustic shortcomings of the auditorium}

The analysis of the room acoustics in the auditorium reveals the potential for the flutter echo effect occurrence. This effect is produced as a result of multiple wave reflections between the side walls in the auditorium, further enhanced by high value of the wave reflection coefficient of the wall made of glass panels.An echogram measured in the middle of the first row of chairs is shown in Fig. 11, by way of an example. Numerous studies [8-11] suggest that the range when echoes are perceived as a nuisance, for delays in excess of ten milliseconds, largely coincides with the sound level decay curve.

The echogram of Fig. 11 allows for identification of a series of impulses the level of which exceeds the decay curve and which are caused by the flutter echo effect. The measurement results are fully corroborated by opinions of teachers who had held classes in the investigated room and who found these echoes to be a nuisance.

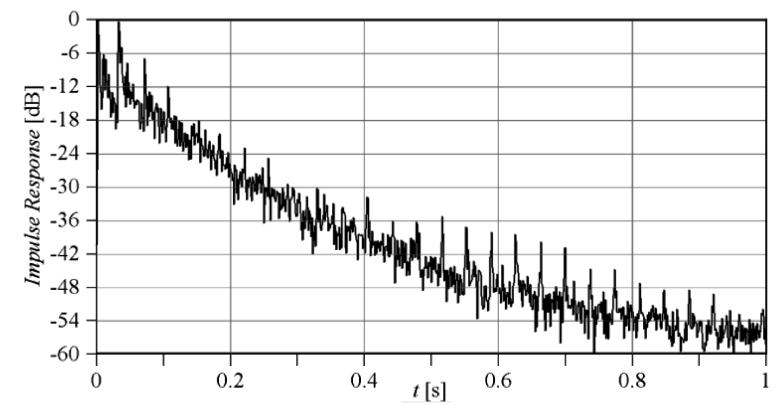

Fig. 11. An echogram measured in the investigated auditorium.

\section{Meeting the design objectives and conformity} to the acoustic design project

The room's acoustics was modernised in accordance with the acoustic design project providing the key requirements relating to acoustical properties of the modernised auditorium, the results of acoustic simulations performed for the proposed room geometry, and the specifications of materials used. Selected parameters are summarised in Table III. The data suggest that the acoustics in the modernised auditorium meets the key requirements relating to speech intelligibility. It is worthwhile to mention, however, that the achieved reverberation times slightly exceed the assumed levels. The sound within the room is not fully unified, as evidenced by the maps in Fig. 10. The values of some indicators obtained by simulations significantly differ from the actual ones.

Selected parameters considered in the evaluation of the auditorium.

TABLE III

\begin{tabular}{|c|c|c|c|}
\hline Parameter & Design objectives & Simulation data (100\% seats occupied) & Measurement data \\
\hline RT & $\begin{array}{l}0.55-0.7 \mathrm{~s}(1 \mathrm{kHz}) \text { stabi- } \\
\text { lised frequency characte- } \\
\text { teristics }\end{array}$ & $\begin{array}{l}-0.54 \mathrm{~s}(1 \mathrm{kHz}) \text { from } 0.53 \mathrm{~s}(500 \mathrm{~Hz}) \\
\text { to } 0.63 \mathrm{~s}(125 \mathrm{~Hz})\end{array}$ & $\begin{array}{l}\text { (estimated for } 100 \% \text { seats occu- } \\
\text { pied) } 0.67 \mathrm{~s}(1 \mathrm{kHz}) \text { from } 0.53 \mathrm{~s} \\
(4 \mathrm{kHz}) \text { to } 0.67 \mathrm{~s}(1 \mathrm{kHz})\end{array}$ \\
\hline RASTI & $\begin{array}{l}\text { at least } 0.65 \text { small varia- } \\
\text { bility over the entire area }\end{array}$ & $0.68-0.72$ & $0.675-0.85$ \\
\hline$C_{50}$ & at least $0 \mathrm{~dB}(1 \mathrm{kHz})$ & $3.8-10.0 \mathrm{~dB}(1 \mathrm{kHz})$ & $3.0-10.5 \mathrm{~dB}(1 \mathrm{kHz})$ \\
\hline Background level & $\operatorname{maximum} L_{T A}=40 \mathrm{~dB}$ & - & $L_{T A}=33 \mathrm{~dB}$ \\
\hline $\begin{array}{l}\text { Uniformity of } \\
\text { sound distribution }\end{array}$ & $\begin{array}{l}\text { Small variability over the } \\
\text { entire area }\end{array}$ & $\begin{array}{l}\text { Max. difference between the } \\
\text { levels }-5 \mathrm{~dB}\end{array}$ & $\begin{array}{l}\text { Max. difference between the } \\
\text { levels }-13 \mathrm{~dB}\end{array}$ \\
\hline
\end{tabular}

\section{Conclusions}

The paper summarises the measurements and evaluations of the acoustics quality in the auditorium No 2 located on the campus of the Mechanical Faculty of the Cracow University of Technology. The main criterion in the evaluation procedure was the speech intelligibility. The analysis of measurement data provided in the study leads to the following conclusions:

- Reverberation time $T_{20}$ in the auditorium falls in the optimum range but the early decay time EDT is 
too short, which gives the overall impression of excessive damping and is indicative of too low energy scattering in the first phase of the impulse response.

- The speech intelligibility based on analysis of several parameters $\left(C_{50 \text { (spav) }}\right.$, RASTI, STI) is found to be good or very good though major differences between individual scores were observed, particularly for lower values of relevant parameters. No areas in the room were found where speech intelligibility level would be significantly different (lower).

- The sound level is strongly dependent on distance from the sound source (the lecturer) which partly results from excessive absorption of energy of first reflections under typical conditions (for the assumed background noise levels that should not strongly affect the speech intelligibility, yet for background noise levels in excess of those stipulated by the normative standards the audibility may deteriorate, particularly at the back of the room).

- Compared to the conditions before implementation of the modernisation program, the acoustic properties of the auditorium significantly improved which is evidenced by improvement of all major parameters.

- Potential occurrence of the flutter echo effect was taken into consideration, as this effect produces some dis- comfort to the teacher, yet it does not typically occur on the way between the teacher and the audience.

\section{References}

[1] D. Wróblewska, Acta Phys. Pol. A 118, 186 (2010).

[2] D. Wróblewska, K. Leo, Acta Phys. Pol. A 121, A-201 (2012).

[3] DIN 18041:2004, Acoustical Quality in Small to Medium-Sized Rooms.

[4] L.G. Marshall, J. Acoust. Soc. Am. 96, 2251 (2004).

[5] M.R. Schroeder, Acustica 49, 179 (1981).

[6] J.S. Bradley, R. Reich, S.G. Norcross, Appl. Acoust. 58, 1820 (1999).

[7] T. Kamisiński, J. Rubacha, A. Pilch, Acta Phys. Pol. A 118, 83 (2010).

[8] F.A. Everest, K.C. Pohlmann, The Master Handbook of Acoustics, McGraw-Hill, Monterey 2001, p. 377.

[9] A.F.B. Nickson, R.W. Muncey, P. Dubout, Acustica 4, 515 (1954).

[10] M. Long, Architectural Acoustics, Elsevier Academic Press, Waltham 2006, p. 741.

[11] H. Niese, Acustica 11, 201 (1961). 